\title{
Preparação para o trabalho na legislação educacional brasileira e educação para carreira
}

\author{
Izildinha Maria Silva Munhoz \\ Lucy Leal Melo-Silva
}

\section{Resumo}

A preparação para o trabalho é um dos objetivos da educação básica brasileira, mas é tema pouco frequente na literatura educacional. Este artigo teórico objetiva: (a) identificar as bases legais da preparação para o trabalho no contexto escolar brasileiro e (b) contribuir para a compreensão da Educação para a Carreira, enquanto modalidade de Orientação Profissional e de Carreira, na preparação para o trabalho dos alunos no contexto da educação básica. Na consulta às bases legais da educação brasileira, observou-se que a legislação e as recomendações do MEC atuais apontam na direção da infusão da temática do trabalho no currículo da educação básica, como acontece nos programas de Educação para Carreira em vários países, segundo revisão da literatura realizada. A inserção de atividades de Educação para Carreira no contexto da educação básica brasileira é apresentada como possibilidade de transpor a lacuna entre o que postulam os documentos legais e a prática em relação à preparação para o trabalho dos alunos.

Palavras-chave: Psicologia Escolar, política educacional, processos legais.

\section{Work preparation in the Brazilian Educational legislation and career education}

\begin{abstract}
Although preparation for work is one of the objectives of the Brazilian basic education, there is not much written material on the subject in Brazil. In this article we aim at identifying the legal basis of work preparation in the Brazilian school context; contributing to the understanding of Career Education as a modality of Professional Orientation, more adequate to basic education. By consulting the Brazilian Education basis, we observed that the laws and the Ministry of Education favor the inclusion of "work" as a theme in the basic education curriculum, similarly to what happens in many countries. The inclusion of Career Education within the basic education curriculum is seen as a possibility to overcome the gap between legislation and the practice regarding students' preparation for work.
\end{abstract}

Keywords: School Psychology, educational policy, legal processes.

\section{Preparación para el trabajo en la legislación educacional brasileña y la educación para la carrera}

\section{Resumen}

La preparación para el trabajo es uno de los objetivos de la educación básica en Brasil, sin embargo suele ser tema poco frecuente en la literatura educacional. Este artículo teórico tiene como objetivos: (a) identificar los fundamentos legales de la preparación para el trabajo en el contexto escolar brasileño y (b) contribuir para la comprensión de la Educación para la Carrera, como modalidad de Orientación Profesional y de Carrera en la preparación para el trabajo de los alumnos en el contexto de la educación básica. Al consultar las bases legales de la educación brasileña se observó que la legislación y las recomendaciones actuales del Ministerio de la Educación y Cultura (MEC) indican la inserción de la temática del trabajo en el currículum de la educación básica, como sucede en programas de Educación para Carrera en varios países de acuerdo con revisión de literatura realizada. Introducir actividades de Educación para Carrera en el contexto de la educación básica brasileña se presenta como posibilidad de superar la distancia entre lo que plantean los documentos legales y la práctica en cuanto a la preparación para el trabajo de los alumnos.

Palabras clave: Psicología escolar, política educacional, procesos legales. 


\section{Introdução}

A questão da relação entre o mundo da educação e o mundo do trabalho é bastante complexa e sujeita a muitas interpretações (e controvérsias). As novas formas de produção do conhecimento, o avanço tecnológico e a globalização estão a exigir um novo profissional e uma preparação que Ihe permita adquirir os conhecimentos, atitudes, habilidades e comportamentos para ser uma pessoa bem preparada para o trabalho.

A concepção da carreira como um processo que se inicia na infância e se estende ao longo da vida confere à escola um papel importante na preparação para o trabalho dos alunos. Organizações internacionais como a UNESCO (United Nations Educational Scientific and Cultural Organization), Banco Mundial e a OCDE (Organização para a Cooperação e Desenvolvimento Econômico) realizaram estudos para identificar como estão configuradas as políticas públicas de Orientação Profissional e de Carreira no contexto escolar em países da Europa, América do Norte, Ásia e América do Sul - Chile (OECD, 2004; Watts \& Fretwell, 2004). Os resultados, apresentados em Munhoz (2010), evidenciaram um aumento crescente de programas de Educação para a Carreira desenvolvidos nas escolas visando contribuir para o desenvolvimento de conhecimentos, atitudes, habilidades e comportamentos que capacitem crianças e jovens para: (a) fazer escolhas educacionais, de formação e profissionais e (b) gerenciar suas carreiras ao longo de toda a vida.

Embora seja o mais comum, o foco dos programas de Educação para a Carreira não deve ser apenas a escolha ou a qualificação para uma profissão específica, mas sim ajudar crianças e jovens a construírem, e se prepararem para realizar, seus projetos de vida. Essa preparação deve ser continuada, em todos os níveis escolares e da carreira, sob o enfoque da aprendizagem ao longo da vida e, na atualidade, cada vez mais sob responsabilidade do indivíduo.

No Brasil, a Lei de Diretrizes e Bases da Educação Brasileira em vigor - LDB 9394/1996 - estabelece em seus primeiros artigos que a educação escolar deverá vincular-se ao mundo do trabalho e à prática social, visando ao pleno desenvolvimento do educando, seu preparo para a cidadania e sua qualificação para o trabalho (Brasil, 1996). Segundo essa lei, a necessária vinculação entre a educação e o trabalho, compreendida no termo Preparação para o Trabalho, deve ser estabelecida nos dois níveis escolares: a Educação Básica (composta pela Educação Infantil, Ensino Fundamental e Ensino Médio) e a Educação Superior.

Este estudo se insere na área da Educação para a Carreira, uma modalidade de intervenção no amplo domínio da tradicional Orientação Profissional/Vocacional, realizada no contexto escolar em muitos países com o objetivo precípuo de relacionar Educação, Trabalho e Carreira e contribuir na preparação para o trabalho dos futuros cidadãos.

A fim de esclarecer a opção conceitual deste estudo, reporta-se a Ribeiro (2011), que discute os diversos conceitos utilizados no Domínio da "Orientação Profissional e de Carreira" e a evolução decorrente das mudanças de para- digmas. No início da área como campo teórico e prático, o termo utilizado foi Orientação Vocacional, pois a ideia que estava embutida:

Era a da vocação como algo a ser descoberto, portanto o trabalho de Orientação Vocacional seria o diagnóstico das características das pessoas e a escolha das ocupações que melhor se ajustassem a esse perfil na filosofia do the right man for the right place - o homem certo para o lugar certo (Ribeiro, 2011, p. 25).

Ao longo do século $X X$, as concepções de escolha e de orientação se modificaram, deixando de ter um enfoque pontual e diagnóstico, para ser concebida como um processo de construção das escolhas e de desenvolvimento vocacional / da carreira. A orientação, que antes privilegiava os momentos de escolha, passa a ser compreendida como um auxílio a qualquer pessoa em qualquer período da vida. A mudança de paradigmas foi acompanhada de mudanças na nomenclatura do campo de estudo.

$\mathrm{Na}$ literatura internacional, observa-se o uso dos conceitos Career Counseling (Aconselhamento de Carreira), Career Guidance (Orientação de Carreira) e Career Development (Desenvolvimento de Carreira). O último conceito tem sido mais utilizado, no cenário internacional, para representar as ideias que no Brasil se reúnem em torno do conceito Orientação Profissional (Ribeiro, 2011). Mais recentemente, no Brasil, o termo Orientação Profissional tem sido ampliado para "Orientação Profissional e de Carreira", podendo incluir a Educação para a Carreira (Career Education), termo considerado apropriado quando a intervenção é realizada em instituições educacionais ao longo da escolaridade.

Neste estudo, utilizar-se-á "Orientação Profissional e de Carreira" como designação de uma grande área. Porém, ao longo do texto, far-se-á uso dos conceitos Orientação Profissional e Orientação Vocacional, quando a legislação ou literatura que estiver sendo abordada empregar tais denominações.

Quanto aos objetivos, este estudo propõe: (a) identificar as bases legais da preparação para o trabalho no contexto escolar brasileiro; (b) contribuir para a compreensão da Educação para a Carreira, enquanto modalidade de Orientação Profissional e de Carreira, na preparação para o trabalho dos alunos no contexto da educação básica.

Para análise das bases legais em relação à Preparação para o Trabalho na Educação Básica, foi realizada pesquisa documental em textos disponíveis nos portais do Ministério da Educação (MEC), do Ministério do Trabalho e Emprego (MTE), da Câmara dos Deputados e do Senado. Neste momento, o foco da consulta direcionou-se para a identificação de referências a respeito da preparação para o trabalho nos pareceres e resoluções que regulamentaram as Diretrizes Curriculares do Ensino Fundamental e Ensino Médio, principalmente a partir das Leis de Diretrizes e Bases da Educação, de 1961 a 1996 (LDB 4024/61; LDB 5692/71; LDB 8044/82; LDB 9394/96). 
Para compreender o contexto de desenvolvimento, concepções e modelos da Educação para a Carreira, foram consultados os indexadores Scielo, PsycARTICLE, Science Direct e Biblioteca Digital de Tese e Dissertações da USP, de 1990 a 2010. Os descritores utilizados foram: preparação+trabalho, educação+carreira, orientação+vocacional, career+education e vocational+guidance+school.

Para alcançar os objetivos propostos, este artigo foi organizado em dois eixos temáticos, constituindo as seções subsequentes do estudo: Bases legais vigentes da preparação para o trabalho no contexto escolar brasileiro e Educação para a Carreira: início e desenvolvimento. Ao final, discutem-se necessidade e possibilidades de inserção de programas e de elaboração de políticas públicas de preparação para o trabalho no contexto da Educação Básica brasileira, nos moldes da Educação para a Carreira.

\section{As bases legais da preparação para o trabalho no contexto escolar brasileiro}

No Brasil, historicamente, as atividades realizadas de forma sistemática em relação à Preparação para o Trabalho no contexto escolar surgiram junto com a Orientação Profissional/Vocacional, na década de 20. Os primeiros Serviços de Orientação Profissional estiveram vinculados à Educação Técnica, com o objetivo de selecionar e orientar jovens para cursos profissionalizantes. Essa experiência se multiplicou para vários pontos do país, com grande número de estudos e produção científica na área.

No plano das legislações, a inserção das atividades de Orientação Profissional/ Vocacional no contexto escolar é sugerida em 1931, na Reforma Francisco Campos, e consolidada nas Leis Orgânicas de Ensino, promulgadas entre 1942 e 1946. As Leis de Diretrizes e Bases da Educação 4024/61 e a 5692/71 tornaram obrigatória a orientação educacional nas escolas, com ênfase no aconselhamento vocacional, ou seja, na escolha profissional (Brasil, 1961, 1971).

A Lei de Diretrizes e Bases de 1971 - LDB 5692/71 institui o segundo grau como profissionalizante, eliminando o dualismo entre escola de $2^{\circ}$ grau e escola técnica, e torna obrigatória a Orientação Educacional nas escolas, "incluindo aconselhamento vocacional, em cooperação com os professores, a família e a comunidade" (Brasil, 1971, Art. 10). O objetivo da lei era oferecer uma formação técnica básica a todos os alunos do Ensino Médio e cabia ao orientador educacional realizar a Orientação Vocacional/ Profissional.

A Lei 7.044/82 alterou dispositivos da lei 5.692/71 referente à profissionalização do ensino de $2^{\circ}$ grau, tornando facultativas a qualificação e habilitação profissional de nível técnico, mas não revogou a obrigatoriedade da Orientação Educacional nas escolas (Brasil, 1982). Entretanto, o fato de ser facultativa, aliada a críticas às práticas da Orientação Vocacional/Profissional realizadas na década de 1980, contribuiu para reduzir sua atuação nas escolas. Tais críticas centravam-se (1) na excessiva ênfase nos processos psicológicos da escolha profissional; (2) nas atuações muito voltadas para a questão da escolha, nos moldes do aconselhamento, e (3) como resultado desta forma de atuação, as atividades dos orientadores foram, e muitas vezes ainda são, consideradas instrumento de reprodução da ideologia dominante e de manutenção das classes sociais.

A Lei de Diretrizes e Bases da Educação vigente LDB 9.394/96 - estabelece que "a educação, dever da família e do Estado, inspirada nos princípios de liberdade e nos ideais de solidariedade humana, tem por finalidade $\underline{0}$ pleno desenvolvimento do educando, seu preparo para o exercício da cidadania e sua qualificação para o trabalho" (Brasil, 1996, art. $2^{\circ}$, grifo nosso). O artigo primeiro da Lei 9.394/96, referente aos objetivos da educação brasileira, estabelece que a educação escolar deve estar "vinculada ao mundo do trabalho e à prática social" $\left(\$ 2^{\circ}\right)$. A ênfase na relação entre Educação e Trabalho é reforçada em seguida no artigo terceiro, que postula entre seus princípios básicos: "a vinculação entre a educação escolar, o trabalho e as práticas sociais" (Brasil, 1996, Inciso XI).

Os Parâmetros Curriculares Nacionais (PCN) de 1997 propõem que no Ensino Fundamental se ofereça uma formação escolar que possibilite aos alunos condições para desenvolverem competência e consciência profissional. Nesse documento, são estabelecidos os temas transversais a serem infundidos em todos os conteúdos: Ética, Saúde, Meio Ambiente, Pluralidade Cultural e Orientação Sexual, eleitos por "envolverem problemáticas sociais atuais e urgentes, consideradas de abrangência nacional e até mesmo de caráter universal" (Brasil, 1997a, p. 45).

Mas e o trabalho? Não seria um problema atual, social, urgente e universal também? É certo que se trata do Ensino Fundamental, mas por que os jovens até os 13/ 14 anos devem ficar alheios à realidade do mundo do trabalho? Em geral, o trabalho é reconhecido como tendo um papel central na vida das pessoas, então por que ele seria menos importante que o desenvolvimento sexual, a necessidade de cuidar da saúde, do ambiente, ser ético e saber conviver com a diversidade cultural?

Nos Parâmetros Curriculares Nacionais (PCN) para o terceiro e quarto ciclo do Ensino Fundamental, $5^{a}$ e $6^{a}$ série e $7^{a}$ e $8^{a}$ série, respectivamente, as relações entre aprendizagem escolar e trabalho aparecem melhor explicitadas:

Hoje em dia não basta visar à capacitação dos estudantes para futuras habilitações nas especializações tradicionais. Trata-se de ter em vista a formação dos estudantes para o desenvolvimento de suas capacidades, em função de novos saberes que se produzem e que demandam um novo tipo de profissional. Essas relações entre conhecimento e trabalho exigem capacidade de iniciativa e inovação e, mais do que nunca, a máxima 'aprender a aprender' parece se impor à máxima aprender determinados conteúdos”. (Brasil, 1998a, p. 44).

A Preparação para o Trabalho vai aparecer de maneira precípua nos documentos legais que respaldam e 
orientam o Ensino Médio. A LDB 9.394/96, originalmente, tratou do Ensino Médio em dois artigos: 35 e 36 . O artigo 35 estabelece como finalidade do Ensino Médio: "a preparação básica para o trabalho e a cidadania do educando, para continuar aprendendo, de modo a ser capaz de se adaptar com flexibilidade a novas condições de ocupação ou aperfeiçoamento posteriores" (Inciso II). Em 1997, o Decreto 2208/ 97 regulamenta o $\S 2^{\circ}$ do art. 36 e os artigos 39 a 42 da Lei 9.394, de 20 de dezembro de 1996, instituindo a Educação Profissional, articulada ao Ensino Médio (Brasil, 1997b).

A Resolução CEB No 3/98 reforça o sentido da LDB ao explicitar que a educação deve se vincular "com o mundo do trabalho e a prática social, consolidando a preparação para o exercício da cidadania e propiciando a preparação básica para o trabalho" (Brasil, 1998c, art. 1º). Segundo o Parecer CEB 15/98, que fundamentou as Diretrizes Curriculares Nacionais para o Ensino Médio, a Preparação para o Trabalho está inevitavelmente ligada à capacidade de aprendizagem e deve destacar a relação da teoria com a prática e a compreensão dos processos produtivos enquanto aplicações dos conhecimentos científicos, "em todos os conteúdos curriculares" (p. 15, grifo do autor). O trabalho deixa de ser obrigação ou privilégio de determinados conteúdos para integrar-se ao currículo como um todo (Brasil, 1998b).

O mesmo Parecer ressalta o significado da Preparação para o Trabalho segundo os artigos 35 e 36 da LDB:

Essa preparação será básica ${ }_{\perp}$ ou seja ${ }_{\perp}$ aquela que deve ser base para a formação de todos e para todos os tipos de trabalho. Por ser básica, terá como referência as mudanças nas demandas do mercado de trabalho, daí a importância da capacidade de continuar aprendendo; não se destina apenas àqueles que já estão no mercado de trabalho ou que nele ingressarão em curto prazo; nem será preparação para o exercício de profissões específicas ou para a ocupação de postos de trabalho determinados. (Brasil, 1998b, p. 15, grifo do autor).

O trabalho se constitui, nessa perspectiva, no princípio organizador do currículo no Ensino Médio. Não se limita ao ensino profissionalizante, "pois todos, independentemente de sua origem ou destino socioprofissional, devem ser educados na perspectiva do trabalho, umas das principais atividades humanas", que envolve a preparação para as escolhas profissionais futuras, o exercício da cidadania e o processo de produção de bens, serviços e conhecimentos com as tarefas laborais que Ihes são próprias (Brasil, 2000a, p. 79).

$\mathrm{Na}$ introdução dos Referenciais Curriculares da Educação Profissional de Nível Técnico (Brasil, 2000b), que definem as linhas mestras do currículo da Educação Profissional, a questão das competências a serem desenvolvidas nos níveis do sistema educacional é assim explicitada: (a) na Educação Básica, como um todo: competências básicas da pessoa e do cidadão, bem como a preparação geral para o trabalho como dimensão da cidadania; (b) no Ensino Mé- dio: as competências estabelecidas em cada área de estudo e (c) na Educação Profissional: as competências profissionais específicas, que têm como requisitos as competências a serem garantidas pela Educação Básica.

Nestes últimos anos, o Ensino Médio no Brasil tem passado por discussões importantes sobre os seus objetivos e função, questionando-se seu caráter academicista e propedêutico, voltado à preparação dos alunos para passar no vestibular. Essas discussões têm ensejado algumas ações por parte do governo, tais como a reformulação do ENEM (Exame Nacional do Ensino Médio) e uma proposta de mudanças nas matrizes curriculares do Ensino Médio. Segundo o Parecer CNE/CP 11/2009, que sintetiza os aspectos essenciais da proposta, a nova organização curricular deve ser organizada "a partir das inter-relações existentes entre os eixos constituintes do Ensino Médio, ou seja, o trabalho, a ciência, a tecnologia e a cultura, tendo o trabalho como princípio educativo" (Brasil, 2009, p. 3, grifo nosso).

Dessa forma, observa-se que a Preparação para o Trabalho, segundo a legislação, deve acontecer desde o Ensino Fundamental e ser inserida em todos os conteúdos - o que sugere ser uma tarefa dos professores. Mas nenhuma palavra é dedicada a como deveria ser realizada essa inserção nem a como preparar os professores para mais essa função.

Na pesquisa efetuada neste trabalho, chama atenção ainda a total omissão nos textos legais sobre desenvolvimento vocacional ou de carreira dos alunos, ou mesmo de referências a como ajudá-los a tomar decisões relativas à carreira, apesar do crescente aumento de cursos técnicos e profissionalizantes. E por que essa omissão? Nossos legisladores identificam vinte e três áreas profissionais na Educação Técnica, abrem a possibilidade de se escolher disciplinas no Ensino Médio, mas a quem deve competir a tarefa de ajudar o aluno em seu desenvolvimento de carreira, a escolher uma área de estudo ou de trabalho?

Como realizar a Preparação para o Trabalho na Educação Básica tal como preconizada nos documentos legais? Que profissionais poderiam contribuir para essa realização? A Educação para a Carreira como modalidade de Orientação Profissional e de Carreira desenvolvida de forma sistemática no contexto escolar em alguns países pode contribuir para responder a essas indagações, como se verá a seguir.

\section{AEducação para a Carreira: início e desenvolvimento}

A Educação para a Carreira (Career Education) refere-se a uma proposta de intervenção adotada em vários países, realizada conjuntamente ao processo educacional, inserida ou infundida no currículo, abrangendo todos os níveis escolares, da Educação Infantil ao Ensino Superior. Esse movimento se estruturou na década de 70, nos Estados Unidos, com Sidney Marland e Kenneth Hoyt, que concebiam Educação para a Carreira como: 
Um esforço do sistema educativo e de toda a comunidade dirigido a contribuir para a reforma educativa ajudando as pessoas com atividades na sala de aula, a relacionar educação e trabalho e a adquirir competências gerais para um positivo desenvolvimento da carreira, de forma a permitir a cada um fazer do trabalho, remunerado ou não, uma parte significativa do seu estilo de vida. (Hoyt, 2005, p. 24).

Hoyt (1995) sempre admitiu a possibilidade de outras definições de Educação para a Carreira, mas para ele seriam quatro os elementos básicos: (a) o conceito de trabalho, (b) o conceito de colaboração, (c) o desenvolvimento de hábitos e atitudes de trabalho e (d) a infusão curricular. O conceito de trabalho é abrangente e envolve tanto atividades remuneradas como não remuneradas; nesse sentido, estudo, afazeres domésticos, voluntariado e atividades de lazer podem ser considerados trabalho. Quanto ao conceito de colaboração, Hoyt (2005) propõe uma relação não apenas cooperativa entre os sistemas de educação em geral e as comunidades ocupacionais, empresarial e industrial. O envolvimento da comunidade deve ser de compartilhar responsabilidades no planejamento, treinamentos, execução e nas avaliações constantes.

Quanto aos hábitos e atitudes em relação ao trabalho, os estudos evidenciam que eles começam a se desenvolver desde a infância e que a escola é um dos primeiros lugares de trabalho onde a criança tem a oportunidade de observar (e aprender sobre) hábitos e comportamentos relacionados ao trabalho (Munhoz \& Melo-Silva, 2011). Dentre as competências para o trabalho que podem ser desenvolvidas desde as séries iniciais, King (2007) identifica: o manejo do tempo e a pontualidade; saber estabelecer objetivos e metas; ter responsabilidade; aprender com os erros; testar as habilidades (autoconhecimento); aprender sobre o próprio estilo de aprendizagem (e como tornar sua aprendizagem melhor); saber ouvir e prestar atenção; e adquirir consciência de carreiras.

A infusão curricular refere-se à disseminação transversal nos conteúdos curriculares de valores, conhecimentos e atitudes relevantes ao desenvolvimento vocacional e da carreira. A Educação para a Carreira é considerada por Hoyt (2005) uma fusão entre o processo de ensino-aprendizagem e o processo de desenvolvimento da carreira, de tal forma que os objetivos a serem atingidos referem-se tanto a competências acadêmicas básicas envolvidas no processo ensino-aprendizagem, como no desenvolvimento vocacional.

Wickwire (2005) considera que programas de Educação para a Carreira podem contribuir para o desenvolvimento ou incremento de: (1) habilidades acadêmicas básicas; (2) bons hábitos de estudo e de trabalho; (3) um conjunto de valores de trabalho que motive o indivíduo a querer trabalhar/ estudar; (4) habilidades para fazer escolhas na carreira, para encontrar e manter o trabalho; (5) habilidades ocupacionais específicas e de relacionamento interpessoal; (6) habilidades de autoconhecimento e conhecimento das oportunidades educacionais e ocupacionais disponíveis; (7) conhecimento dos meios disponíveis para a educação continuada e permanente; (8) habilidades para buscar, conseguir e manter um emprego e/ou tomar decisões de carreira; (9) disponibilidade para utilizar o tempo livre de forma produtiva, através de trabalho não remunerado, como voluntariado ou no ambiente familiar; e (10) conhecimento dos meios disponíveis para mudar as próprias opções de carreira (Munhoz \& Melo-Silva, 2011).

Um dos argumentos para a Educação para a Carreira nas escolas é justamente fortalecer a motivação dos alunos para o estudo e a aprendizagem através da percepção da ligação entre o que se aprende na escola e o mundo do trabalho. Hoyt (1995) acrescenta que inserir no cotidiano da escola atividades para relacionar trabalho e educação implica defender o trabalho como um esforço consciente e comprometido com aquilo que se decidiu fazer. Sentir orgulho de fazer, fazer bem feito e buscar a superação seriam metas a serem atingidas nessa perspectiva de trabalho.

Em seu modelo de Educação para a Carreira, o autor propõe que as atividades destinadas a promover o desenvolvimento da carreira no contexto escolar incluam quatro eixos fundamentais: (a) tomar consciência do significado do trabalho, de carreiras e de profissões; (b) exploração de carreiras, que envolve conhecer a si mesmo e ao mundo do trabalho; (c) aprender a tomar decisões - aprender a fazer escolhas ao longo da vida, inclusive, mas não só, de uma carreira; e (d) lidar com as mudanças na carreira, tão frequentes no mundo atual (Hoyt, 1995).

Ao analisar a situação da Educação para a Carreira neste início de século XXI em vários países, Watts (2001) identificou três formas diferentes de estruturação das atividades: (1) estratégias aditivas - inseridas como um tema à parte do currículo, com atividades e objetivos diversos, tais como autoconhecimento, informação profissional e escolha de cursos e carreira; (2) estratégias infusivas - integradas ao currículo, com o trabalho e a carreira compondo um tema transversal; (3) estratégias mistas - realizadas como uma disciplina própria incluída na grade horária ou fazendo parte do conteúdo de uma disciplina.

As estratégias infusivas são a pedra angular da Educação para a Carreira, mas também o seu maior desafio (Jenschke, 2002; OECD, 2004; Pinto, Taveira, \& Fernandes, 2003; Rodrigues-Moreno, 2008). Segundo Rodrigues-Moreno (2008), nas estratégias infusivas é preciso levar em consideração o nível de desenvolvimento das diferentes etapas da criança e do adolescente e adaptar os objetivos ao desenvolvimento social e moral dessas idades.

Entretanto, para a autora, "não é fácil integrar os conceitos vocacionais nos currículos dos distintos países em enfoques educativos" (p. 36). Rodrigues-Moreno (2008) aponta como dificuldades: (1) as questões envolvidas no planejamento curricular (como fazer, quem deve fazer / coordenar); (2) o aspecto motivacional: como facilitar para que a escola e os professores se disponham a trabalhar com a Educação para a Carreira; e (3) os fatores histórico-culturais, tais como o distanciamento de crianças e adolescentes (principalmente, mas não só, das camadas mais abastadas) da realidade 
do trabalho e a exigência cada vez maior de preparação, assim como a dificuldade em "traduzir" para as crianças as questões do trabalho (Munhoz \& Melo-Silva, 2011).

Rodrigues - Moreno (2008) considera fundamental que as escolas ofereçam aos alunos conteúdos bem estruturados e coerentes sobre o sistema econômico em que vivem e as características do mundo do trabalho que os rodeiam. "Numa sociedade democrática, os jovens devem ter uma preparação básica sobre seu papel como produtores, consumidores e cidadãos, como também noção das relações entre estes três aspectos da vida econômica" (p.28).

A inserção de tais conteúdos no currículo escolar passa necessariamente pelos professores a despeito das estratégias que forem estruturadas, pois os professores desempenham um papel importante no desenvolvimento pessoal e vocacional de seus alunos. Por estarem próximos dos alunos, ao longo da Educação Básica, tornam-se referências, não só como modelos de profissionais, mas também como fonte de apoio e informação para as dúvidas e preocupações vocacionais dos alunos, como mostram os estudos de Gomes \& Taveira (2001), Munhoz (2010) e Pinto e cols. (2003).

Em Portugal, onde as atividades de Educação para a Carreira são garantidas pela legislação, Pinto e cols. (2003) realizaram estudos com professores e sugeriram incluir, no currículo de formação dos professores, módulos de estudo sobre o desenvolvimento vocacional como processo ao longo da vida, sua relação com o desenvolvimento acadêmico e sobre a "influência do professor na promoção do desenvolvimento vocacional dos estudantes" (p. 54).

No Brasil, a análise de algumas propostas de implantação de programas de Orientação Vocacional no contexto educacional evidencia a necessidade e a dificuldade de se trabalhar com os professores nas escolas (Affonso \& Sposito, 2002; Soares, 1993). Soares (1993) relata a dificuldades para conseguir o apoio e o interesse dos professores, que afirmam não dispor de tempo para integrar mais uma atividade, além da sobrecarga que existe. Munhoz (2010) identifica como os professores participam, de forma não planejada ou sistemática, do desenvolvimento vocacional dos alunos e sugere formas de preparação dos professores para a participação direta ou indireta em embasar essas ações de Educação para a Carreira.

\section{Considerações Finais}

As seções anteriores permitiram observar que a Preparação para o Trabalho no contexto escolar não pode se restringir apenas à aquisição do conhecimento ou de habilidades acadêmicas básicas. A escola, como lugar de aprendizado, convivência e formação, apresenta-se como espaço privilegiado para o desenvolvimento de hábitos, atitudes, valores, habilidades e pensamento crítico e é, inevitavelmente, um lugar onde projetos de vida são construídos (e às vezes destruídos) e não pode ser omissa em relação à sua importância nesta questão.
Em termos da legislação, pode-se identificar que, desde 1924, marco inicial das primeiras atividades no Brasil, até as leis de ensino compreendidas entre 1930 e 1971, a Preparação para o Trabalho nas escolas foi confiada a orientadores educacionais, como parte das atividades de Aconselhamento Vocacional, voltado para a escolha profissional. A partir da LDB 9.394/96, os documentos legais deixam de se referir explicitamente ao Aconselhamento Vocacional ou à Orientação Educacional para referir-se a uma preparação básica para o trabalho, obrigatória na Educação Básica como um todo (mas de forma mais contundente no Ensino Médio), e uma profissionalização opcional na Educação Profissional de Nível Técnico.

Segundo a legislação analisada, a preparação geral para o trabalho envolve tanto os conteúdos e competências básicas para a inserção no mundo do trabalho, como noções e valor do trabalho, produtos do trabalho e condições de produção, e outros considerados importantes ou indispensáveis para a formação, treinamento e atuação profissional futura. De acordo com os documentos legais, essas competências deveriam ser desenvolvidas dentro dos conteúdos, inseridas no currículo, tanto do Ensino Fundamental quanto do Ensino Médio. Como visto na seção anterior, esses são conteúdos altamente pertinentes a programas de Educação para a Carreira.

Em seus trabalhos, Hoyt $(1995,2005)$ sempre defendeu a ideia de que os conteúdos escolares deveriam ter como eixo central o trabalho. Não é essa a posição das autoras deste artigo. O que se concebe, para o contexto brasileiro, é que o trabalho seja considerado um tema transversal ao currículo desde as séries iniciais do Ensino Fundamental, oferecendo aos alunos conteúdos bem estruturados e coerentes sobre o sistema econômico em que vivem e as características do mundo do trabalho que os rodeia.

Defende-se abordar o trabalho com os alunos, nos diferentes conteúdos, como atividade que as pessoas realizam para seu sustento, para a manutenção e desenvolvimento da civilização e uma forma de realização pessoal e humana. Por outro lado, não se defende neste estudo que criança precisa trabalhar, no sentido de trabalho infantil, remunerado e/ou explorado, que pode restringir o desenvolvimento da criança e é proibido por lei, sendo seu maior beneficiário o capital.

A preparação para o trabalho dentro da Educação para a Carreira deve acontecer segundo o enfoque do trabalho educativo, historicamente contextualizado e crítico, que acontece (ou deveria acontecer) na família, na escola e na comunidade, o qual toda criança ou adolescente pode e deve fazer, visando à construção da carreira e ao exercício da cidadania. O que se defende para o contexto escolar brasileiro é que, de preferência, se insira conceitos relativos ao desenvolvimento da carreira e do mundo do trabalho no currículo, sob a supervisão de um orientador especializado, com a colaboração de um grupo de apoiadores, como professores, pais e outras pessoas da comunidade.

Entretanto, a inserção de programas de Educação para a Carreira no contexto educacional brasileiro exige que o conhecimento na área se amplie e se diversifique, pois a realidade brasileira é muito heterogênea. Há várias questões 
fundamentais a serem investigadas, tais como: o significado de trabalho - para alunos, professores, pais, comunidade escolar; a preparação de professores e orientadores; de que modo realizar a infusão da temática trabalho; em quais conteúdos; segundo qual modelo?

Neste estudo, concebe-se certa convergência entre os princípios da Preparação para o Trabalho e da Educação para a Carreira, porém com maior amplitude de ação e perspectivas para o segundo conceito em consonância com as diretrizes internacionais, para a intersecção das áreas educação, trabalho e carreira. Ao discutir estratégias para implantação da Educação para a Carreira no Brasil, Munhoz (2010) sugere três eixos de ação básicos: (a) Implementação nas escolas: difundir nas escolas e na comunidade as ideias básicas da Educação para a Carreira e preparar grupos de profissionais ou pais interessados na elaboração e implantação de programas de Educação para a Carreira; (b) Formação de professores: ações voltadas para a inserção de módulos acerca do desenvolvimento vocacional nos conteúdos programáticos da formação pedagógica dos professores; (c) Políticas públicas: “reunir grupos e associações, como a ABOP - Associação dos Orientadores Profissionais e outros, interessados em fomentar a discussão para a elaboração de políticas públicas que incentivem a realização no contexto escolar de ações que relacionem Educação, TrabaIho e Carreira fundamentada no princípio de orientação ao longo da vida" (p. 282).

Esse poderá ser um passo importante para o Brasil, que precisa diminuir o abismo entre as suas políticas públicas de preparação para o trabalho e as políticas públicas de países mais desenvolvidos em Orientação Profissional e Educação para a Carreira. Como menciona Silva (2010): "Enquanto a prioridade na Europa, Estados Unidos, Austrália e outros países é conduzir uma reforma das políticas de Orientação Profissional, mal se discute, no Brasil, como construir essas políticas" (p. 37, grifos do autor).

Finalizando, a Educação para a Carreira se apresenta como um modelo de intervenção adequado ao contexto atual da sociedade pós-moderna, tecnológica e globalizada e contempla, com seu enfoque educativo, a possibilidade de abranger um número expressivo de crianças e jovens, atualmente desprovidos de intervenções que ajudem a articular educação e trabalho. Ao compreender a preparação para o trabalho como dimensão da cidadania, pretende-se contribuir para a preparação dos jovens para um engajamento democrático, ativo e crítico não apenas profissional, mas também pessoal e social.

\section{Referências}

Affonso, R. M. L., \& Sposito, L. L. (2002). Oficinas de orientação profissional no contexto escolar: a construção de um modelo. Em M. C. P. Lassance, A. Paradiso, M. P. Bardagi, M. Sparta S. L. \& Frischenbruder (Orgs.), Intervenção e compromisso social. São Paulo: Vetor.
Decreto $n^{\circ}$ 2.208. (1997b, 17 de abril). Regulamenta o parágrafo $2^{\circ}$ do art. 36 e os arts. 39 a 42 da Lei 9.394, de 20 de dezembro de 1996. Brasília, DF: Presidência da República, Casa Civil.

Gomes, I. T., \& Taveira, M. C. (2001). Educação para a carreira e formação de professores. Relatórios de Investigação, Centro de Estudos em Educação e Psicologia, Universidade do Minho. Braga, Portugal: Editora da Universidade.

Hoyt, K. B. (1995) El concepto de educación para la carrera y sus perspectivas. Em M. L. Rodríguez (Org.), Educación para la carrera y diseño curricular: teoría y práctica de programas de educación para el trabajo (pp. 15-37). Barcelona: Universitat de Barcelona.

Hoyt, K. B. (2005). Career education as a federal legislative effort. Em K. B. Hoyt (Org.), Career education: history and future (pp. 3-74). Oklahoma: National Career Development Association.

Jenschke, B. (2002). Educação profissional em escolas em uma perspectiva internacional. Em R. S. Levenfus \& D. H. P. Soares, Orientação vocacional ocupacional: novos achados teóricos, técnicos e instrumentais para a clínica, a escola e a empresa (pp. 23-31). Porto Alegre: Artmed.

King, L. (2007). Making the link: helping children link school habits with the world of work. South Carolina: YouthLight, Inc.

Lei $n^{\circ}$ 4024, de 20 de dezembro de 1961. (1961). Estabelece as Diretrizes e Bases da Educação Nacional. Brasília, DF: Presidência da República, Casa Civil.

Lei $n^{\circ}$ 5692, de 11 de agosto de 1971. (1971). Diretrizes e Bases para o ensino de $1^{\circ}$ e $2^{\circ}$ graus. Brasília, DF: Presidência da República, Casa Civil.

Lei $n^{\circ}$ 7.044, de 18 de outubro de 1982. (1982). Altera dispositivos da Lei $n^{\circ}$ 5.692, de 11 de agosto de 1971, referentes à profissionalização do ensino de $2^{\circ}$ grau. Brasília, DF: Presidência da República, Casa Civil.

Lei $n^{\circ}$ 9.394, de 20 de dezembro de 1996. (1996). Diretrizes e Bases da Educação Nacional. Brasília, DF: Presidência da República, Casa Civil.

Munhoz, I. M. S. (2010). Educação para a carreira e representações sociais de professores: limites e possibilidades na educação básica. Tese de Doutorado, Faculdade de Filosofia Ciências e Letras de Ribeirão Preto/USP, Ribeirão Preto.

Munhoz, I. M. S., \& Melo-Silva, L. L. (2011). Educação para a Carreira: concepções, desenvolvimento e possibilidades no contexto brasileiro. Revista Brasileira de Orientação Profissional, 12(1), 37-48.

OECD - Organization for Economic Co-Operation and Development. (2004). Career guidance and public policy bridging the gap. Paris: OECD. 
Parâmetros curriculares nacionais terceiro e quarto ciclos do ensino fundamental. (1998a). Estabelece os parâmetros curriculares nacionais. Brasília, DF: Ministério da Educação e do Desporto. Secretaria de Educação Fundamental.

Parâmetros curriculares nacionais. (1997a). Estabelece os parâmetros curriculares nacionais. Brasília, DF: Ministério da Educação e do Desporto. Secretaria de Educação Fundamental.

Parâmetros curriculares nacionais: ensino médio. (2000a). Estabelece parâmetros curriculares. Brasília, DF: Ministério da Educação. Secretaria de Educação Média e Tecnológica.

Parecer CEB n. 15/98. (1998b). Diretrizes Curriculares Nacionais para o Ensino Médio. Brasília, DF: Ministério da Educação e do Desporto. Conselho Nacional de Educação. Câmara de Educação Básica.

Parecer CNE/CP No: 11/2009. Brasil (2009). Proposta de experiência curricular inovadora do Ensino Médio. Brasília, DF: Ministério da Educação. Conselho Nacional de Educação,

Pinto, H. R., Taveira, M. C., \& Fernandes, M. E. (2003) Os professores e o desenvolvimento vocacional dos estudantes. Revista Portuguesa de Educação, 16(1), 37-58.

Referências Curriculares da Educação Profissional de Nível Técnico. (2000b). Brasília, DF: Ministério da Educação. Conselho Nacional de Educação. Câmara de Educação Básica.

Resolução n. 3, de 26 de junho de 1998. (1998c). Diretrizes Curriculares Nacionais para o Ensino Médio. Brasília, DF: Ministério da Educação e do Desporto. Conselho Nacional de Educação. Câmara da Educação Básica.
Ribeiro, M. A. (2011). Orientação profissional: uma proposta de guia terminológico. Em: M. A. Ribeiro \& L. L. Melo-Silva, Compêndio de orientação profissional e de carreira (Vol. 1, pp.23-66). São Paulo, Vetor.

Rodrigues - Moreno, M. L. (2008). A educação para a carreira: aplicação à infância e à adolescência. Em M. C. Taveira \& J. T. Silva, Psicologia vocacional: perspectivas para a intervenção. Coimbra, Portugal: Imprensa da Universidade de Coimbra.

Silva, F. F. (2010). Construção de projetos profissionais e redução da vulnerabilidade social: subsídios para políticas públicas de orientação profissional no ensino médio. Tese de Doutorado, Instituto de Psicologia, Universidade de São Paulo, São Paulo.

Soares, D. H. P. L. (Org.). (1993). Pensando e vivendo a orientação profissional. São Paulo: Summus.

Watts, A. G. (2001) Career education for young people: rationale and provision in the UK and others European countries. International Journal Educational Vocational Guidance, 1(3), 209-222.

Watts, A. G., \& Fretwell, D. H. (2004). Public policies for career development: case studies and emerging issues in developing and transition economies. Washington, DC: World Bank.

Wickwire, P. N. (2005). An AACE snapshot of career education from 1970 to the present. Em K. B. Hoyt (Org.), Career education: history and future (pp. 127-134). Oklahoma: National Career Development Association.

\section{Sobre as autoras}

Izildinha Maria Silva Munhoz (nimunhoz@terra.com.br)

Psicóloga e pedagoga. Doutora em Psicologia pelo Programa de Pós-Graduação em Psicologia da Faculdade de Filosofia, Ciências e Letras de Ribeirão Preto da Universidade de São Paulo. Pesquisadora nas linhas de pesquisa: (1) Desenvolvimento Profissional e Práticas Pedagógicas e (2) Orientação Profissional, Educação e Desenvolvimento da Carreira. Endereço: Rua Bento Ferreira, 486, apto. 801, 38060-240. Mercês, Uberaba/MG.

Lucy Leal Melo-Silva (lucileal@ffclrp.usp.br)

Professora Doutora do Departamento de Psicologia da Faculdade de Filosofia, Ciências e Letras de Ribeirão Preto. Autora de artigos e organizadora de livros na área de Psicologia e da Orientação Profissional. Pesquisadora CNPq, na linha de Pesquisa: Orientação Profissional, Educação e Desenvolvimento de Carreira: diagnóstico e intervenção. Endereço: Av. Bandeirantes, 3900 - CEP: 14040-901, Ribeirão Preto/SP

Estudo baseado na elaboração da Tese de Doutorado da primeira autora, orientada pela segunda, junto ao Programa de Pós-Graduação em Psicologia da Faculdade de Filosofia, Ciências e Letras (FFCLRP) da Universidade de São Paulo. 